Article

\title{
Enhanced Wear Resistance of 316 L Stainless Steel with a Nanostructured Surface Layer Prepared by Ultrasonic Surface Rolling
}

\author{
Cong Wang ${ }^{1}$, Jing Han ${ }^{1,2, *}$, Jiyun Zhao ${ }^{1}$, Yuanming Song ${ }^{1}$, Jiaxiang Man ${ }^{1}$, Hua Zhu ${ }^{1}$, \\ Jiapeng Sun ${ }^{3}$ and Liang Fang ${ }^{4}$ \\ 1 School of Mechanical and Electrical Engineering, China University of Mining and Technology, \\ Xuzhou 221116, China; TS18050062A31@cumt.edu.cn (C.W.); jyzhao@cumt.edu.cn (J.Z.); \\ TS18050060A31@cumt.edu.cn (Y.S.); manjxcumt@163.com (J.M.); hzhu@cumt.edu.cn (H.Z.) \\ 2 Jiangsu Engineering Technology Research Center on Intelligent Equipment for Fully Mining and Excavating, \\ Xuzhou 221116, China \\ 3 College of Mechanics and Materials, Hohai University, Nanjing 210098, China; sunpengp@hhu.edu.cn \\ 4 State Key Laboratory for Mechanical Behavior of Materials, Xi'an Jiaotong University, Xi'an 710049, China; \\ fangl@xjtu.edu.cn \\ * Correspondence: hanjing@cumt.edu.cn
}

Received: 19 March 2019; Accepted: 22 April 2019; Published: 25 April 2019

check for updates

\begin{abstract}
The low hardness and poor wear resistance of AISI $316 \mathrm{~L}$ austenitic stainless-steel sabotage its outer appearance and shorten its service life when it is subjected to sliding. In this paper, the single-pass ultrasonic surface rolling (USR) process was used to modify the surface of $316 \mathrm{~L}$ austenitic stainless steel. A nanostructured surface layer with a depth span of $15 \mu \mathrm{m}$ was fabricated. Dry wear tests of USR samples were performed on a ring-on-block tester at room temperature, and the results were compared with those for the as-received sample. The USR sample showed a significant reduction in wear mass loss and an improved hardness, as well as a decreased surface roughness. The detailed wear mechanism was also investigated by SEM observations of the worn surfaces. It was indicated that oxidation and abrasive wear, accompanied by mild adhesion, dominated the wear of USR 316 L stainless steel at both low and high speeds. The superior wear performance of USR $316 \mathrm{~L}$ was attributed to its nanostructured surface layer, which was characterized by a high hardness and thereby suppressed the severe abrasive wear. The results provided an alternative approach to modifying the surface of 316 L stainless steel, without changing its surface chemical components.
\end{abstract}

Keywords: 316 L; surface nanocrystallization; wear mechanism; ultrasonic surface rolling

\section{Introduction}

As one of the typical stainless steels, $316 \mathrm{~L}$ stainless steel has a medium strength, excellent toughness, good plasticity and formability, and good corrosion and oxidative resistance [1,2]. Thus, it has been widely used in marine, petrochemical, and energy development and other fields. However, $316 \mathrm{~L}$ stainless steel possesses a low hardness. As a result, it suffers from poor wear resistance, which sabotages its outer appearance and shortens its service life, when it is subjected to sliding [3,4]. It is thus of great significance to improve the wear resistance of $316 \mathrm{~L}$ stainless steel in order to broaden its application.

In the last two decades, surface nanocrystallization (SNC) has become an attractive surface modifying method. This method involves coating a nanostructure layer on the metal surface using severe plastic deformation technology, without changing the surface chemical components [5-8]. So far, several methods have been developed to prepare SNC on the metal surface, such as surface mechanical 
attrition treatment (SMAT) [9,10], surface mechanical grinding treatment (SMGT) [11,12], surface mechanical rolling treatment (SMRT) [13], ultrasonic shot peening (USP) [14,15] and supersonic fine particles bombarding (SFPB) [16]. These approaches have also been used to improve the surface and bulk properties of AISI $316 \mathrm{~L}$ stainless steel. Lu et al. found that a gradient nanostructured surface (GNS) layer was formed on $316 \mathrm{~L}$ stainless steel by means of SMRT, which facilitated a significant enhancement in fatigue strength [17]. Sara Bagherifard et al. reported that the nanolayer in AISI 316 L, formed by severe shot peening, could increase the surface roughness and surface wettability, which was highly important for biomedical application [18]. The enhancement of oxidation resistance at high temperatures was also found in SMAT-treated AISI 316 L [19].

Ultrasonic surface rolling (USR) is a novel and effective surface strengthening technique, which combines static load with ultrasonic energy to impact the material surface. Compared with conventional techniques, USR holds several advantages, such as ease of operation, low cost, and high efficiency. It has been used to reduce the stress concentration, improve the hardness, enhance the wear performance, and augment the fatigue characteristics of several metals [20-22]. Zhao et al. found that the USR TC11 titanium alloy experienced a $46.6 \%$ increase in the micro-hardness of the topmost surface and a $19.3 \%$ improvement in fatigue strength, compared to the original sample [23]. A significant improvement $(52.6 \%)$ in the micro-hardness of USR $40 \mathrm{Cr}$, accompanied by a decrease in friction coefficient and wear rate, was also obtained by Wang et al. [24]. Moreover, Wang et al. reported that USR, assisted by electropulsing, can further improve the surface microhardness and rotating bending fatigue strength of AISI 304 stainless steel $[25,26]$. While SNC has shown its advantage in improving the surface properties and bulk mechanical properties of various metals, limited attempts have been made to modify $316 \mathrm{~L}$ by the USR method. Moreover, multi-pass USR is generally required to obtain satisfying surface properties, which unfavorably increases the complexity and decreases the efficiency of processing.

In this paper, single-pass USR was adopted to modify the surface of AISI $316 \mathrm{~L}$ stainless steel. Micro-analytical techniques (OM and TEM) were used to characterize the microstructures of the surface modification layer. The wear behaviors under dry friction conditions were discussed. The detailed wear mechanisms were also investigated by SEM observations of the worn surfaces.

\section{Materials and Methods}

\subsection{Sample Preparation}

In this study, a commercial hot-extruded AISI $316 \mathrm{~L}$ austenitic stainless-steel bar, with nominal chemical compositions of $0.03 \mathrm{wt} \% \mathrm{C}, 10.7 \mathrm{wt} \% \mathrm{Ni}, 16.72 \mathrm{wt} \% \mathrm{Cr}, 2.12 \mathrm{wt} \% \mathrm{Mo}, 1.01 \mathrm{wt} \% \mathrm{Mn}$, $0.03 \mathrm{wt} \% \mathrm{Si}, 0.0165 \mathrm{wt} \% \mathrm{~S}$ and $0.042 \mathrm{wt} \% \mathrm{P}$, was employed. The initial material was machined into a round bar, with a diameter of $30 \mathrm{~mm}$ and a length of $500 \mathrm{~mm}$.

\subsection{Ultrasonic Surface Rolling Process}

A schematic illustration of an ultrasonic surface rolling (USR) setup, in which an ultrasonic apparatus was installed in a CNC lathe, is shown in Figure 1. During the USR processing, a carbide alloy rolling ball, driven by ultrasonic waves, was applied to achieve a high-frequency impact and rolled on the samples under a static force. In the present work, the following USR parameters were used: a rolling ball diameter of $14 \mathrm{~mm}$, an ultrasonic vibration frequency of $28 \mathrm{kHz}$, a vibration amplitude of $5 \mu \mathrm{m}$ and an applied static force of $300 \mathrm{~N}$. A single-pass USR process was used to enhance the wear-resistance of AISI $316 \mathrm{~L}$ stainless steel. While a multi-pass USR process is generally employed to obtain the gradient nanocrystalline structure, it is energy-extravagant and efficiency-deficient. 


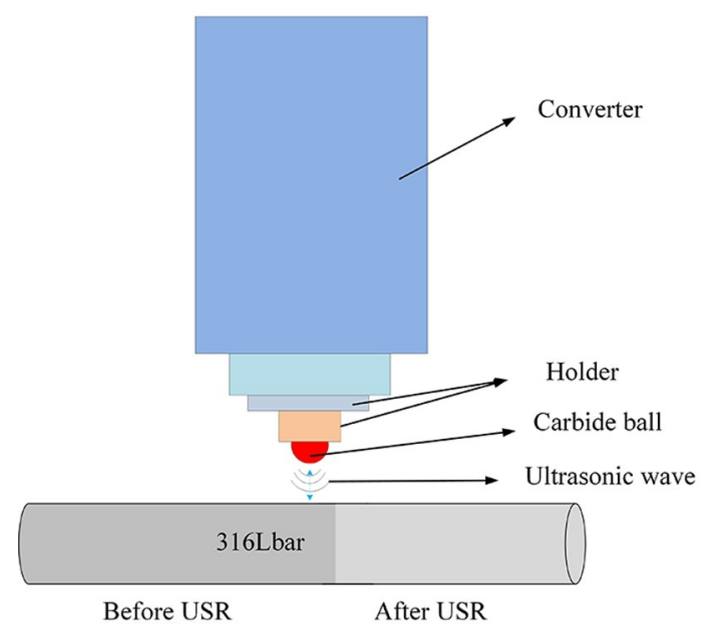

Figure 1. Schematic illustration of the ultrasonic surface rolling (USR) setup.

\subsection{Wear Test, Microstructure Characterization and Hardness Test}

The wear tests were performed on the M-2000 tribometer (Shunmao, Jinan, China) in a ring-on-block mode under dry wear conditions at room temperature, as illustrated in Figure 2. The rings were made of AISI 52100 steel, with a HRC hardness of 63 and a diameter of $30 \mathrm{~mm}$. The applied load was $150 \mathrm{~N}$, and the wear duration was $15 \mathrm{~min}$ at a sliding speed of 200 and $400 \mathrm{rpm}$, respectively. Before and after the wear test, ultrasonic cleaning of the samples in acetone was performed, and the samples were weighed to obtain the mass loss. In order to guarantee the stability of the wear data, each wear test was repeated three times under the same testing conditions.

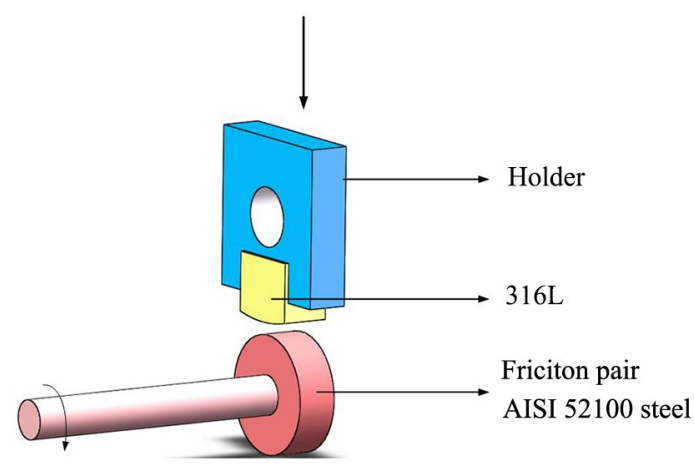

Figure 2. Schematic illustration of the ring-on-block wear test principles.

Microstructure observations were performed using optical microscopy (OM, Olympus BX51M, Tokyo, Japan) and a Transmission Electron Microscope (TEM, JEM 2100, JEOL Ltd., Tokyo, Japan). Samples for OM analysis were prepared via grinding, polishing, and etching in an electrolyte of $90 \%$ alcohol and 10\% perchloric acid. For TEM characterization, a cross-sectional foil was mechanically cut containing the treated surface accompanied by carefully grinding, and further prepared via twin-jet polishing, with a solution of $2 \%$ perchloric ethanol at $253 \mathrm{~K}$. The wear scars were analyzed using a desktop Scanning Electron Microscope (SEM, Phenom, Thermo Fisher Scientific, Waltham, MA, USA). The micro-hardness was measured using a HXD-1000TC microhardness-testing instrument (Shanghai Taiming Optical Instrument Co., Ltd., Shanghai, China) on the surface of the sample. The load was $0.98 \mathrm{~N}$, and the holding duration was $10 \mathrm{~s}$. The average micro-hardness value of ten test points was used. 


\section{Results and Discussion}

\subsection{Microstructures of the USR Surface Layer}

Figure 3 shows the typical cross-sectional OM images of the as-received sample and the USR sample. The microstructure of the as-received sample was mainly composed of equiaxed austenitic grains, with a mean size of $19 \mu \mathrm{m}$, embedded with a few annealing twins, as shown in Figure 3 a. Notably, plastic deformation and grain refinements were observed in the top-surface layer, as shown in Figure 3a. The depth of the surface grain-refined layer extended to around $15 \mu \mathrm{m}$. The original austenitic grains in the subsurface were compressed and elongated in the direction parallel to the specimen surface, indicating a plastic deformation zone due to ultrasonic striking during USR. In the plastic deformation zone, deformation twins within grains were clearly observed.

Typical cross-sectional TEM micrographs, shown in Figure $4 \mathrm{a}-\mathrm{c}$, characterized the microstructures of the USR sample's surface. It was apparent that equiaxed nanograins were formed in the top-surface layer of the USR sample, indicating surface nanocrystallization by USR [27,28]. The corresponding SAED patterns confirmed the nanograin microstructures of the USR sample's surface and indicated that the nanostructured surface layer is composed of martensite and austenite grains with random crystallographic orientations. The grain size ranged from approximately 6 to $15 \mathrm{~nm}$, which was comparable with that generated by SMAT [29], while it was much smaller than that generated by SMRT [17]. The equiaxed nanograins were generated through dynamic recrystallization under severe plastic deformation, induced by USR. The detailed formation of the nanograins for coarse-grained polycrystals by USR involved various dislocation activities and the development of grain boundaries, which were similar to the results obtained by SMAT [27]. The high density of dislocations and dislocation tangles within the austenitic grains in the plastic deformation zone provided evidence for the above inference (Figure 4b). Moreover, increased deformation twins were visible in the plastic deformation zone (Figures $3 \mathrm{a}$ and $4 \mathrm{c}$ ), which indicated that mechanical twinning played an important role in the formation of nanograins. Because $316 \mathrm{~L}$ stainless steel exhibits a low stacking fault energy, mechanical twinning prevails in server plastic deformation. The high plastic strain subjected to USR played a crucial role in the formation of the nanostructure, and it facilitated dislocation generation and suppressed dislocation annihilation [30]. The surface nanocrystallization induced by USR has been found in several metals, such as 40Cr [24], 304 stainless steel [31], and Ti6Al4V [32]. The present nanostructure surface layer was relatively thin because of the insufficient plastic deformation subjected to the single-pass USR. The thick nanostructure surface layer could be obtained by increasing the passes of USR.

(a)

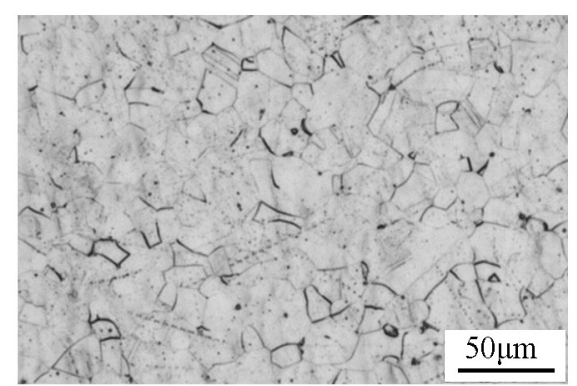

(b)

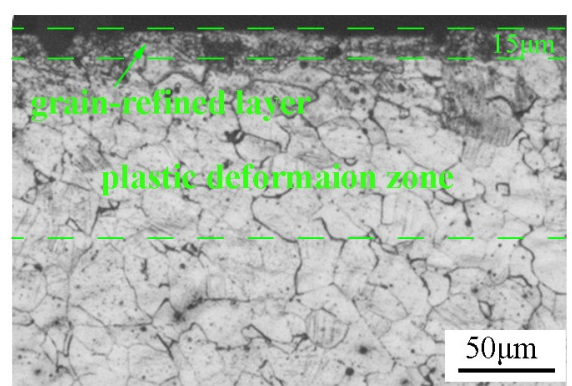

Figure 3. Typical cross-sectional optical microscopy (OM) of (a) the as-received sample and (b) the USR sample in the top-surface layer. 

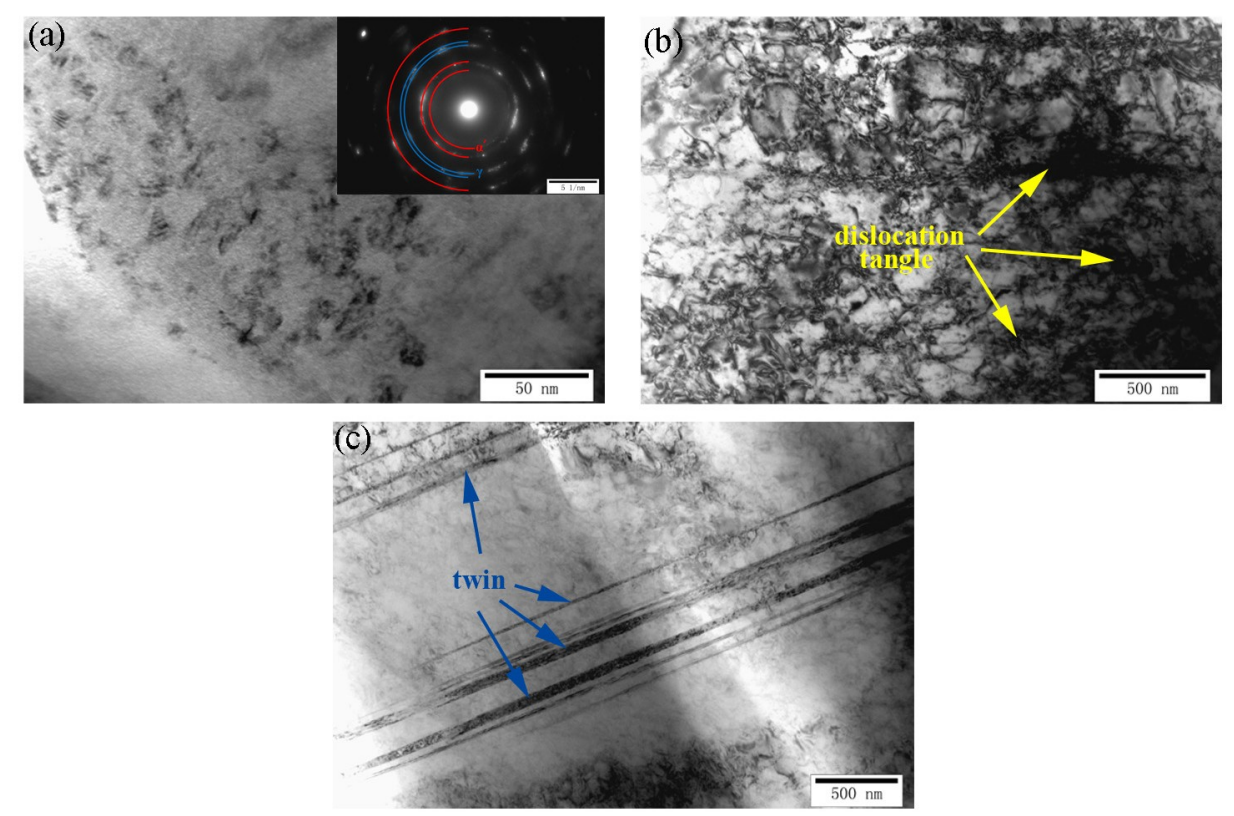

Figure 4. Bright field TEM image of the USR sample (a) in the top-surface layer, $(\mathbf{b}, \mathbf{c})$ in the deformation zone. The insert in (a) shows the corresponding SAED patterns.

\subsection{Mechanical and Wear Behaviors}

Figure 5a shows the surface Vickers hardness of the as-received and the USR samples. The USR sample experienced a $61 \%$ increase in hardness (increasing from $177 \mathrm{HV}$, which was the level of the as-received specimen, to around $290 \mathrm{HV}$ ). The improved hardness was ascribed to the grain refinement and the high dislocation density of the nanostructured surface layer, induced by USR. Herein, the strengthening or hardening of the grain refinement made a major contribution, which can be expressed based on the well-known Hall-Petch equation.

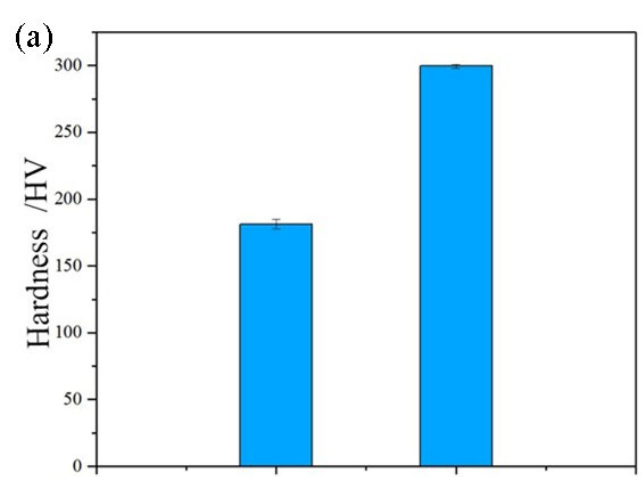

as-received sample USR sample

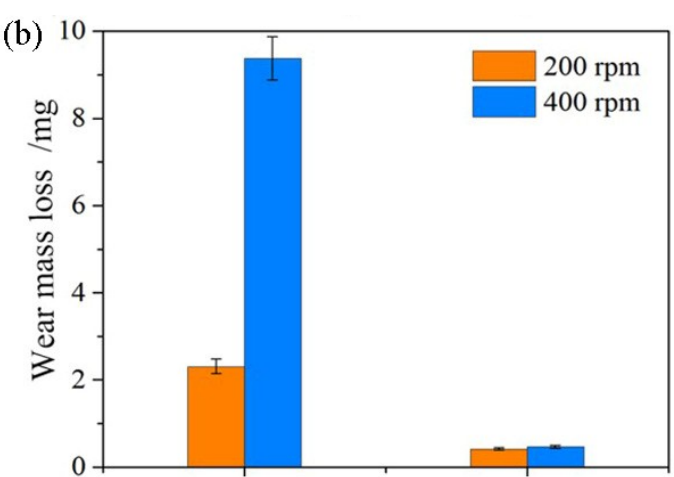

as-received sample USR sample

Figure 5. The hardness (a) and wear mass loss (b) of the USR sample, compared to as-received sample.

Figure $5 \mathrm{~b}$ shows the wear mass loss of the USR sample, compared to the as-received sample, at two different wear speeds. It was apparent that the USR-treated sample suffered a low wear mass loss, indicating a high wear resistance. The advantage of the USR sample was especially prominent at a high wear speed. At a high wear speed, its wear mass loss was reduced by $\sim 20$ times, compared to the as-received sample. Moreover, the wear loss of the as-received sample increased significantly with an increase in the wear speed. In contrast, the USR sample showed a less significant speed-dependent wear behavior.

SEM observations and EDS analysis of the worn surfaces were conducted to understand the material removal and dissection of the wear mechanisms. Figures 6 and 7 show SEM micrographs of 
the typical worn surfaces of the USR sample and the as-received sample at two different wear speeds, respectively. At a low speed (200 rpm), both the as-received and the USR samples displayed abrasive wear and oxidation, marked by the obvious furrow trace and a large oxidation zone, as shown in Figure $6 \mathrm{a}, \mathrm{b}$ and Figure $7 \mathrm{a}, \mathrm{b}$. The obviously increased oxygen content in the black zone on the wear track implied the occurrence of oxidation induced by friction heat, as shown in Figure 6e,f and Figure 7e,f. A trivial plastic flow was also discernible, implying the occurrence of mild adhesive wear. At a high speed (400 rpm), the relatively smooth wear track and furrow trace demonstrated slight adhesive wear and abrasive wear for the USR sample, as illustrated in Figure $6 \mathrm{c}, \mathrm{d}$. In contrast, severe plastic flow and adhesive wear occurred on the wear tracks of the as-received sample, as shown in Figure 7c,d. The severe plastic flow and adhesion phenomena were related to the relatively low microhardness of the as-received sample, compared with its friction couple. The prevailing oxidation wear at a low wear speed was generally related to the initial oxidation film on the metal's surface. Raw AISI 316 L stainless steel and its AISI 52100 steel friction couple were covered by an oxidation film. Therefore, wear indeed occurred between the two oxidation films at a low speed, and thus the oxidation prevailed, but the wear mass loss was low. Increasing the wear velocity led to a direct metal-to-metal contact. Thus, the abrasive wear became dominant, accompanied by a high wear mass loss. These findings were consistent with those from a previous report on the wear of steel [33].

Due to its low hardness, $316 \mathrm{~L}$ stainless steel generally shows a low wear resistance, especially when the abrasive wear is dominant. After the USR processing, a significantly improved hardness was obtained because of the resultant nanostructured surface layer. This hard and nanostructured surface layer can withstand severe adhesive wear and plastic flow, which thus played a critical role in enhancing the wear resistance of $316 \mathrm{~L}$ stainless steel. Furthermore, an additional roughness test was performed. The average surface roughness was $R_{\mathrm{a}} 0.04 \mu \mathrm{m}$ and $R_{\mathrm{a}} 0.8 \mu \mathrm{m}$ for the USR sample and the as-received sample, respectively. This demonstrated that USR reduced surface roughness, which was consistent with previous reports on other metals [24]. Generally, the roughened surface tended to reduce the wear mass loss. This reinforced the critical role of the nanostructured surface layer in enhancing the wear resistance of $316 \mathrm{~L}$ stainless steel. However, the initial roughness, after the wear test, was completely changed (Figure 6) because of the severe oxidation and abrasive wear. Therefore, we considered that the roughness had a less significant influence on the wear of $316 \mathrm{~L}$ stainless steel under the present condition. Moreover, the different subsurface damages and cracking may be related to the enhanced wear resistance of the USR sample, which will be further addressed in future works.
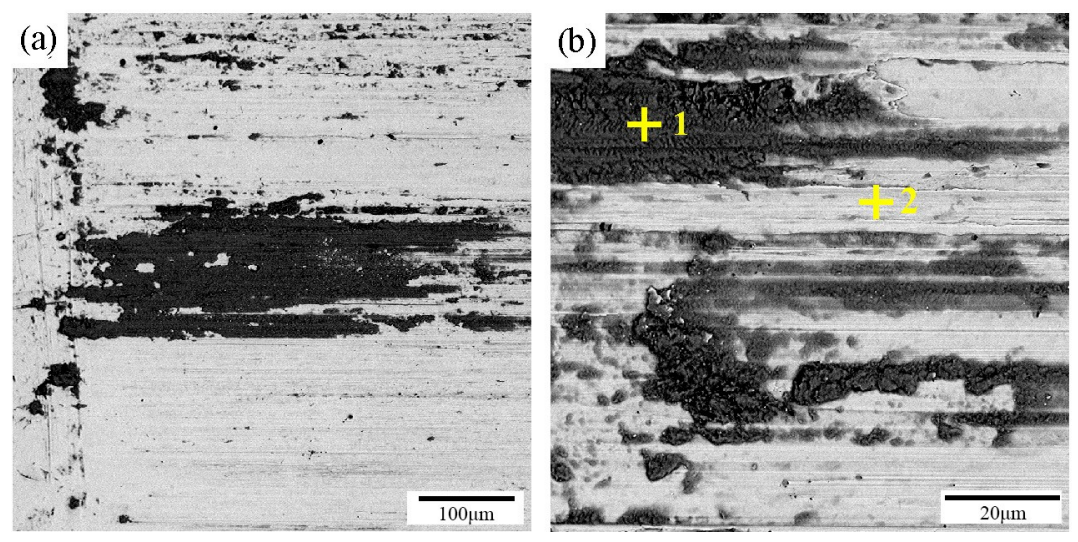

Figure 6. Cont. 

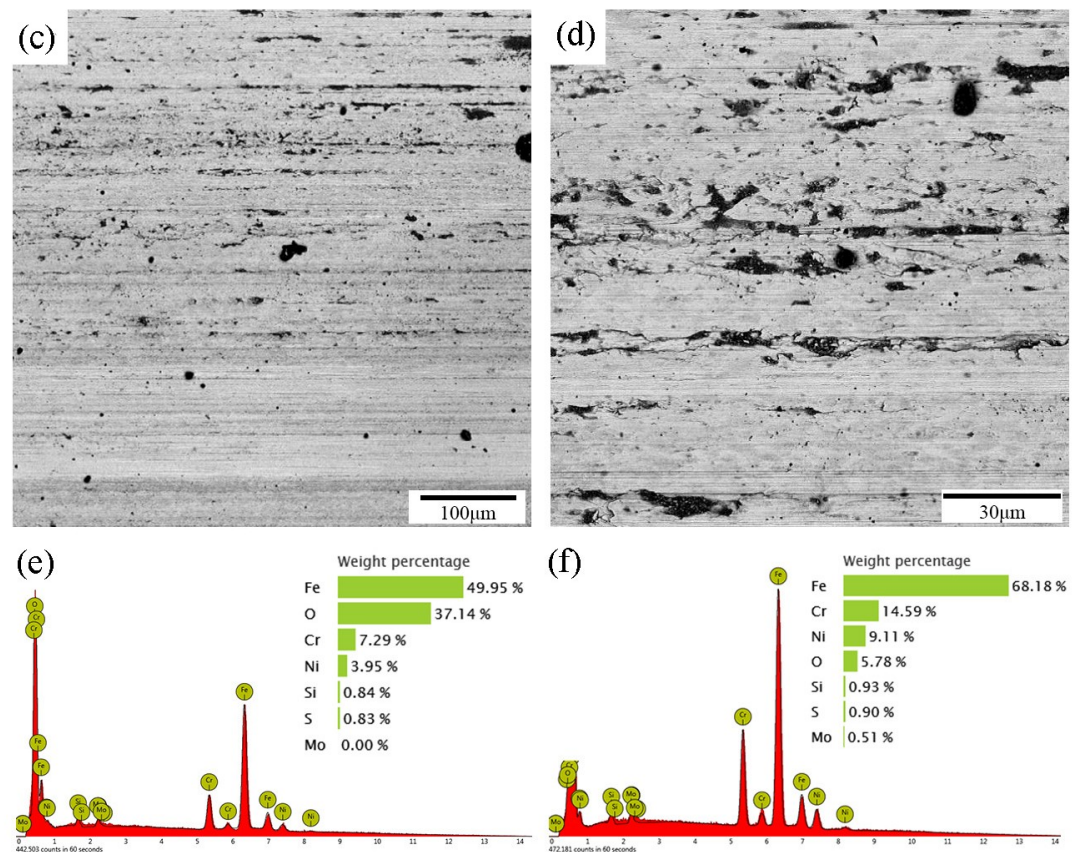

Figure 6. SEM images of the typical worn surfaces of the USR sample at $200 \mathrm{rpm}(\mathbf{a}, \mathbf{b})$ and $400 \mathrm{rpm}$ $(\mathbf{c}, \mathbf{d})$. The right-hand graph is an enlargement of the left-hand graph. The result of EDS analysis (e,f), obtained from the region marked by 1 and 2 in (b).
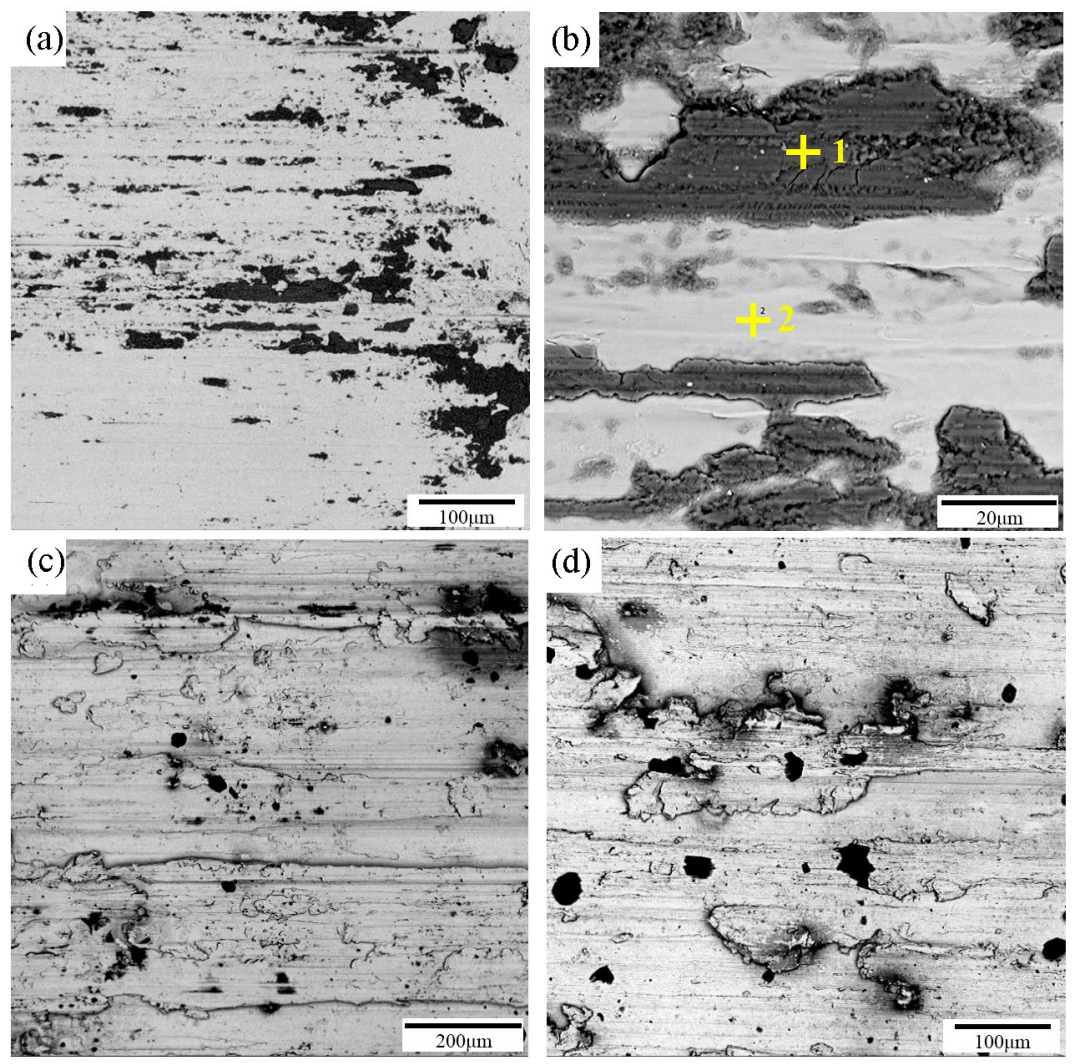

Figure 7. Cont. 
(c)

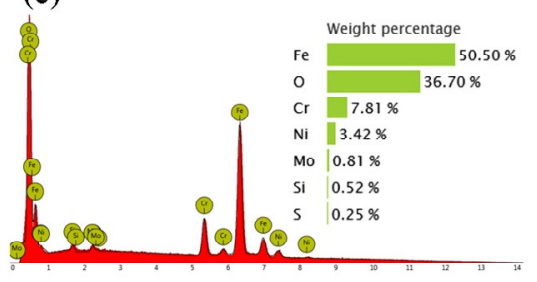

(f)

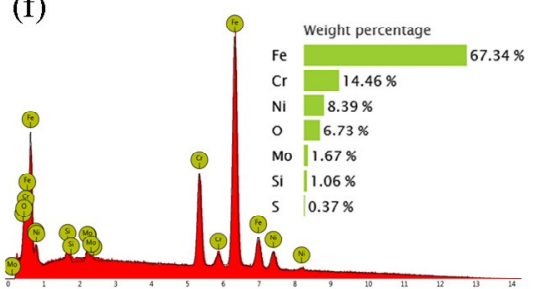

Figure 7. SEM images of the typical worn surfaces of the as-received sample at $200 \mathrm{rpm}(\mathbf{a}, \mathbf{b})$ and $400 \mathrm{rpm}(\mathbf{c}, \mathbf{d})$. The right-hand graph is an enlargement of the left-hand graph. The result of EDS analysis $(\mathbf{e}, \mathbf{f})$, obtained from the region marked by 1 and 2 in $(\mathbf{b})$.

\section{Conclusions}

In this paper, the single-pass ultrasonic surface rolling process was used to modify the surface of AISI $316 \mathrm{~L}$ stainless steel to improve its surface properties. The main conclusions that were drawn are as follows:

- A nanostructured surface layer, with a depth span of $15 \mu \mathrm{m}$, was fabricated on AISI $316 \mathrm{~L}$ stainless steel through USR processing.

- USR 316 L stainless steel exhibited a significantly improved hardness and enhanced wear resistance, as well as a decreased surface roughness, compared with the as-received sample.

- Oxidation and abrasive wear, accompanied by mild adhesive wear, contorted the wear of USR $316 \mathrm{~L}$ stainless steel at both low and high wear speeds.

- The superior wear-resistant performance of USR 316 L stainless steel was attributed to the nanostructured surface layer, which had a high hardness and thereby withstood the severe abrasive wear.

Author Contributions: Conceptualization, J.H., J.S., J.Z. and L.F.; Methodology, C.W. and Y.S.; Validation, J.H. and J.S.; Formal Analysis, J.H. and J.Z.; Investigation, C.W., Y.S. and J.M.; Resources, J.H., J.Z. and L.F.; Data Curation, J.H.; Writing-Original Draft Preparation, C.W.; Writing-Review and Editing, J.H. and H.Z.; Visualization, C.W. and J.M.; Supervision, J.H.; Project Administration, J.H.; Funding Acquisition, J.H. and H.Z.

Funding: This research was funded by the Fundamental Research Funds for the Central Universities (No. 2015XKMS019), the National Natural Science Foundation of China (Nos. 51675519, 51775546), the A Project Funded by the Priority Academic Program Development of Jiangsu Higher Education Institutions.

Conflicts of Interest: The authors declare no conflict of interest.

\section{References}

1. Chen, X.H.; Lu, J.; Lu, L.; Lu, K. Tensile properties of a nanocrystalline $316 \mathrm{~L}$ austenitic stainless steel. Scr. Mater. 2005, 52, 1039-1044. [CrossRef]

2. Lo, K.H.; Shek, C.H.; Lai, J.K.L. Recent developments in stainless steels. Mater. Sci. Eng. R Rep. 2009, 65, 39-104. [CrossRef]

3. Wang, P.F.; Han, Z. Friction and wear behaviors of a gradient nano-grained AISI $316 \mathrm{~L}$ stainless steel under dry and oil-lubricated conditions. J. Mater. Sci. Technol. 2018, 34, 1835-1842. [CrossRef]

4. Wang, B.; Yao, B.; Han, Z. Annealing Effect on wear resistance of nanostructured 316 L stainless steel subjected to dynamic plastic deformation. J. Mater. Sci. Technol. 2012, 28, 871-877. [CrossRef]

5. Zhou, L.; Long, C.; He, W.; Tian, L.; Jia, W. Improvement of high-temperature fatigue performance in the nickel-based alloy by LSP-induced surface nanocrystallization. J. Alloy. Compd. 2018, 744, 156-164. [CrossRef]

6. Liu, C.; Zheng, H.; Gu, X.; Jiang, B.; Liang, J. Effect of severe shot peening on corrosion behavior of AZ31 and AZ91 magnesium alloys. J. Alloy. Compd. 2019, 770, 500-506. [CrossRef]

7. Lu, K.; Lu, J. Nanostructured surface layer on metallic materials induced by surface mechanical attrition treatment. Mater. Sci. Eng. A 2004, 375-377, 38-45. [CrossRef] 
8. Roland, T.; Retraint, D.; Lu, K.; Lu, J. Enhanced mechanical behavior of a nanocrystallised stainless steel and its thermal stability. Mater. Sci. Eng. A 2007, 445, 281-288. [CrossRef]

9. Sun, Y. Sliding wear behaviour of surface mechanical attrition treated AISI 304 stainless steel. Tribol. Int. 2013, 57, 67-75. [CrossRef]

10. Zhang, H.; Hei, Z.K.; Liu, G.; Lu, J.; Lu, K. Formation of nanostructured surface layer on AISI 304 stainless steel by means of surface mechanical attrition treatment. Acta Mater. 2003, 51, 1871-1881. [CrossRef]

11. Li, W.L.; Tao, N.R.; Lu, K. Fabrication of a gradient nano-micro-structured surface layer on bulk copper by means of a surface mechanical grinding treatment. Scr. Mater. 2008, 59, 546-549. [CrossRef]

12. Liu, X.; Zhang, H.; Lu, K. Formation of nano-laminated structure in nickel by means of surface mechanical grinding treatment. Acta Mater. 2015, 96, 24-36. [CrossRef]

13. Xin, C.; Sun, Q.; Xiao, L.; Sun, J. Biaxial fatigue property enhancement of gradient ultra-fine-grained Zircaloy-4 prepared by surface mechanical rolling treatment. J. Mater. Sci. 2018, 53, 12492-12503. [CrossRef]

14. Liu, G.; Lu, K.; Lu, J. Surface nanocrystallization of $316 \mathrm{~L}$ stainless steel induced by ultrasonic shot peening. Mater. Sci. Eng. A 2000, 286, 91-95. [CrossRef]

15. Zhu, L.; Guan, Y.; Lin, J.; Zhai, J.; Xie, Z. A nanocrystalline-amorphous mixed layer obtained by ultrasonic shot peening on pure titanium at room temperature. Ultrason. Sonochem. 2018, 47, 68-74. [CrossRef] [PubMed]

16. Ba, D. Surface nanostructure formation mechanism of 45 steel induced by supersonic fine particles pombarding. J. Univ. Sci. Technol. Beijing Miner. Metall. Mater. 2008, 15, 561-567. [CrossRef]

17. Huang, H.; Wang, Z.; Lu, B.J.; Lu, K. Fatigue behaviors of AISI 316 L stainless steel with a gradient nanostructured surface layer. Acta Mater. 2015, 87, 150-160. [CrossRef]

18. Bagherifard, S.; Slawik, S.; Fernández-Pariente, I.; Pauly, C.; Mücklich, F.; Guagliano, M. Nanoscale surface modification of AISI 316 L stainless steel by severe shot peening. Mater. Des. 2016, 102, 68-77. [CrossRef]

19. Benafia, S.; Retraint, D.; Yapi Brou, S.; Panicaud, B.; Grosseau Poussard, J.L. Influence of surface mechanical attrition treatment on the oxidation behaviour of 316 L stainless steel. Corros. Sci. 2018, 136, 188-200. [CrossRef]

20. Zhang, Q.; Hu, Z.; Su, W.; Zhou, H.; Liu, C.; Yang, Y.; Qi, X. Microstructure and surface properties of 17-4PH stainless steel by ultrasonic surface rolling technology. Surf. Coat. Tech. 2017, 321, 64-73. [CrossRef]

21. Li, G.; Qu, S.G.; Pan, Y.X.; Li, X.Q. Effects of the different frequencies and loads of ultrasonic surface rolling on surface mechanical properties and fretting wear resistance of $\mathrm{HIP} \mathrm{Ti}_{6} \mathrm{Al}_{4} \mathrm{~V}$ alloy. Appl Surf. Sci. 2016, 389, 324-334. [CrossRef]

22. Li, G.; Qu, S.; Xie, M.; Li, X. Effect of ultrasonic surface rolling at low temperatures on surface layer microstructure and properties of HIP Ti-6Al-4V alloy. Surf. Coat. Tech. 2017, 316, 75-84. [CrossRef]

23. Zhao, X.; Xue, G.; Liu, Y. Gradient crystalline structure induced by ultrasonic impacting and rolling and its effect on fatigue behavior of TC11 titanium alloy. Results Phys. 2017, 7, 1845-1851. [CrossRef]

24. Ting, W.; Dongpo, W.; Gang, L.; Baoming, G.; Ningxia, S. Investigations on the nanocrystallization of 40cr using ultrasonic surface rolling processing. Appl. Surf. Sci. 2008, 255, 1824-1829. [CrossRef]

25. Wang, H.; Yang, X.; Li, H.; Song, G.; Tang, G. Enhanced fatigue performance and surface mechanical properties of AISI 304 stainless steel induced by electropulsing-assisted ultrasonic surface rolling process. J. Mater. Res. 2018, 33, 3827-3840. [CrossRef]

26. Wang, H.; Song, G.; Tang, G. Enhanced surface properties of austenitic stainless steel by electropulsing-assisted ultrasonic surface rolling process. Surf. Coat. Tech. 2015, 282, 149-154. [CrossRef]

27. Lu, K.; Hansen, N. Structural refinement and deformation mechanisms in nanostructured metals. Scr. Mater. 2009, 60, 1033-1038. [CrossRef]

28. Lin, Y.; Lu, J.; Wang, L.; Xu, T.; Xue, Q. Surface nanocrystallization by surface mechanical attrition treatment and its effect on structure and properties of plasma nitrided AISI 321 stainless steel. Acta Mater. 2006, 54, 5599-5605. [CrossRef]

29. Roland, T.; Retraint, D.; Lu, K.; Lu, J. Fatigue life improvement through surface nanostructuring of stainless steel by means of surface mechanical attrition treatment. Scr. Mater. 2006, 54, 1949-1954. [CrossRef]

30. Lu, J.; Luo, K.; Zhang, Y.; Sun, G.; Gu, Y.; Zhou, J.; Ren, X.D.; Zhang, X.C.; Zhang, L.F.; Chen, K.M.; et al. Grain refinement mechanism of multiple laser shock processing impacts on ANSI 304 stainless steel. Acta Mater. 2010, 58, 5354-5362. [CrossRef] 
31. Ye, C.; Telang, A.; Gill, A.S.; Suslov, S.; Idell, Y.; Zweiacker, K.; Wiezorek, J.M.K.; Zhou, Z.; Qian, D.; Mannava, S.R. Gradient nanostructure and residual stresses induced by Ultrasonic Nano-crystal Surface Modification in 304 austenitic stainless steel for high strength and high ductility. Mater. Sci. Eng. A 2014, 613, 274-288. [CrossRef]

32. Liu, J.; Suslov, S.; Vellore, A.; Ren, Z.; Amanov, A.; Pyun, Y.; Martini, A.; Dong, Y.; Ye, C. Surface nanocrystallization by ultrasonic nano-crystal surface modification and its effect on gas nitriding of $\mathrm{Ti}_{6} \mathrm{Al}_{4} \mathrm{~V}$ alloy. Mater. Sci. Eng. A 2018, 736, 335-343. [CrossRef]

33. Lim, S.C.; Ashby, M.F.; Brunton, J.H. Wear-rate transitions and their relationship to wear mechanisms. Acta Metall. 1987, 35, 1343-1348. [CrossRef]

(C) 2019 by the authors. Licensee MDPI, Basel, Switzerland. This article is an open access article distributed under the terms and conditions of the Creative Commons Attribution (CC BY) license (http://creativecommons.org/licenses/by/4.0/). 